\title{
Causes, impact and control of overbreak in underground excavations
}

\author{
HK Verma, RD Dwivedi, P Pal Roy and PK Singh \\ CSIR-Central Institute of Mining and Fuel Research \\ Dhanbad, India \\ drharsh77@gmail.com
}

\begin{abstract}
Drilling and blasting has been a preferred method of rock excavation world-wide. Blasting inevitably causes damage to the peripheral rock mass, which culminates in the form of overbreak and damaged zone. Damage or overbreak not only endangers the safety of structure and cost escalation but also delayed completion. Too large damage zone endangers the safety of the front line workers due to reduction of stand-up time especially for poor rock mass. Functionality and postconstruction performance of structures get affected due to large extent of damage zone, if not taken care in time. Field investigations were carried out at five different Himalayan tunnels to formulate an empirical equation for predicting blastinduced overbreak for wide range of rock mass quality wherein $Q$ values ranged between 0.03 and 17.8. The proposed equation involves parameters like specific charge, perimeter charge factor, maximum charge per delay, rock mass quality $(Q)$, advancement and confinement factors. These parameters are readily available at the site without any difficulty. Nearly 113 experimental blasts were monitored and data so collected were used to formulate an index termed as scale effect $\left(S_{i}\right)$, which is the ratio of tunnel crosssectional area and block size of rock mass. It is revealed that when $S_{i}$ becomes greater than 4 , the range of overbreak lied between 8 and $25 \%$.
\end{abstract}

Keywords - rock mass damage; blasting; overbreak; Maximum charge per delay; scale effect

\section{INTRODUCTION}

Drilling and blasting method (DBM) is globally used for rock excavation due to low investment, cheap explosive energy, easy acceptability among the stakeholders, possibility of dealing with different shapes and sizes of openings and reasonably faster rate of advancement in a suitable geotechnical mining condition. This makes DBM a preferred method of rock excavation [1].

DBM inevitably damage surrounding rock mass due to formation of network of fine cracks leading to safety and stability problems. Rock mass damage zone surrounding an underground opening consists of over-break zone (failed zone), damaged zone and a disturbed zone. The three zones of damage are shown in Fig 1. The over-break zone represents the zone beyond the minimum excavation line of the designed periphery from where rock blocks/slabs detach from the rock mass. It is a measure of difference in excavation between 'as designed profile' and 'as excavated profile'. Over-break varies from 5 to $30 \%$ which incurs significant cost and increases cycle time of the tunnelling operation. Over-break assessment in tunnels assumes greater importance to minimize cycle time operation and optimisation. Usually host of geotechnical parameters, blast design and operational parameters and explosive properties influence it. Over-break may also occur due to the effect of the ground conditions and the nature of excavation being adopted [2].

The factors influencing the smoothness and softness of the perimeter can be classified into four categories viz. drilling accuracy, perimeter hole spacing and loading (charging), treatment of first row in-holes and geology [3]. Zone immediately beyond the over-break zone is damaged zone. The damaged zone is a zone of influence around tunnel beyond the over-break zone. The irreversible changes in the rock mass properties take place in this zone due to the presence of fine networks of micro-cracks and fractures induced by the blasting and excavation process. This zone is characterized by deterioration in mechanical and physical properties and increase in transmissivity properties. The disturbed zone is a zone in the rock mass immediately beyond the damaged zone where changes in the rock mass properties are insignificant and reversible. This zone is dominated by changes in stresses and hydraulic permeability.

Over-break as well as damaged zone has significant impact on the project cost, construction period, safety and performance of the underground structures. In the case of the civic tunnels, damaged zone can adversely affect the stability of the structure and hence they need to be accounted for while designing support system for openings.

In light of the above observations, field investigations were carried out at the sites of five hydroelectric projects to assess various aspects of overbreak resulting in blasting. Using data obtained from the field, an empirical equation has been developed to estimate the overbreak (\%) during construction of civic tunnels.

\section{FIELD INVESTIGATIONS}

Field experiments were carried out to look into the insight of these influencing parameters at five tunnel construction sites. These sites are integral parts of three major hydroelectric projects located in Hiamalaya. They include Access Tunnels (AA10R and AA7) from Pump Storage Plant (PSP) of THDC India Limited at Tehri, Head Race Tunnel (HRT) of Singoli- 
Bhatwari Hydroelectric Power Project (SBHEP) at Rudraprayag, HRT and Bypass Tunnel (BPT) of Tapovan Visnhnugaad Hydroelectric Power Project (TVHEP) at Tapovan. The data was obtained from 113 blasts undertaken at such construction sites. Rock mass characterisation, blast vibration monitoring, overbreak assessment and estimation of damaged zone were carried out for each blast. Figure 2 shows photograph of head race tunnel of Singoli-Bhatwari Hydro project site at Rudraprayag.

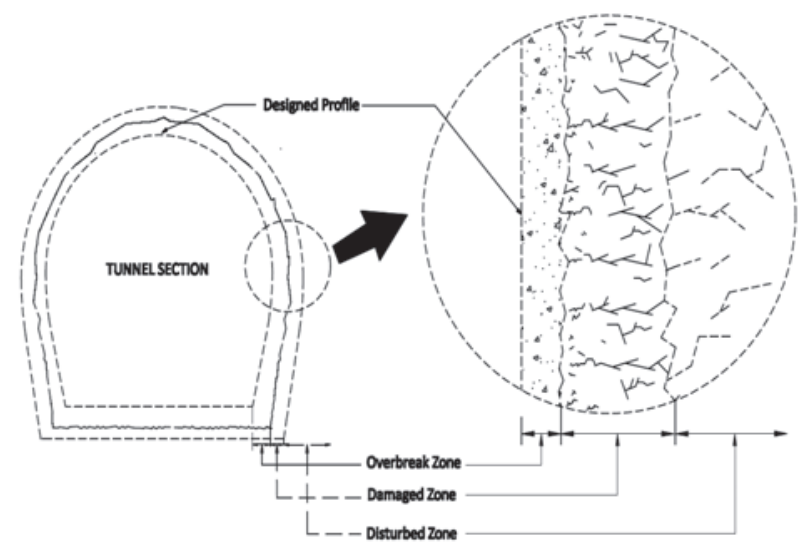

Fig. 1. Blast induced rock mass damage zone around an underground opening

All experimental blasts were closely monitored and all drilling related data, especially perimeter holes and holes in the penultimate row and their corresponding depths were collected. Charge loading parameters such as explosive consumption in a hole, total charge, initiation sequence, maximum charge per delay were recorded meticulously. Pull obtained in each round was obtained after surveying of tunnel profile and advancement. Factors on advancement and confinement were calculated for each blast to represent different features of underground excavation. The data parameters, which were collected, are described below.

- Specific charge $(q)\left(\mathrm{kg} / \mathrm{m}^{3}\right)$ : It is defined to be the ratio of total quantity of explosive and volume of broken rock.

- Maximum charge per delay $(W)(\mathrm{kg})$ : It is the maximum quantity of explosive fired in a delay series.

- Perimeter charge factor $\left(q_{p}\right)\left(\mathrm{kg} / \mathrm{m}^{3}\right)$ : Similar to specific charge, it is the quantity of explosive used in perimeter holes and the volume of rock corresponding to burden of the contour holes.

- Advancement factor $\left(A_{f}\right)$ : It is ratio of pull (l) and hole depth $(d)$ in a blast round.

- Confinement factor $\left(C_{f}\right)$ : It is ratio of hole depth $(d)$ and cross-sectional area of tunnel $(a)$.

Rock mass characterisation has been carried out in terms of tunnel rock mass quality, $Q$. This system of rock mass characterization has been recommended specifically for tunnels and caverns with an arched roof. It is observed that $Q$-system is a preferred method of classification of rockmass for civil construction such as tunnels and caverns for various purposes like support design and engineering classification of rock mass. In $Q$-system, Stress Reduction factor $(S R F)$ is one of the parameters which accounts for active stresses during construction of an underground opening and that is why $Q$-system has been selected for rock mass characterisation in the present study.

In all the experimental sites, $Q$ ranges from 0.03 to 17.8 indicating that the suggested method could be applicable to a wide range of rock mass under non-squeezing ground condition.

Overbreak is the volume of rock outside the minimum excavation line removed during excavation operations [4]. Conventionally, overbreak is expressed in percent of theoretical rock volume produced in each round of blast. In the present study, it has been measured using a total station survey equipment after each round of blast covering wide range of $Q$ values. Table-1 shows the general information and various rock-strength parameters. Figure 3 shows experimental investigations of rock core samples in the laboratory.

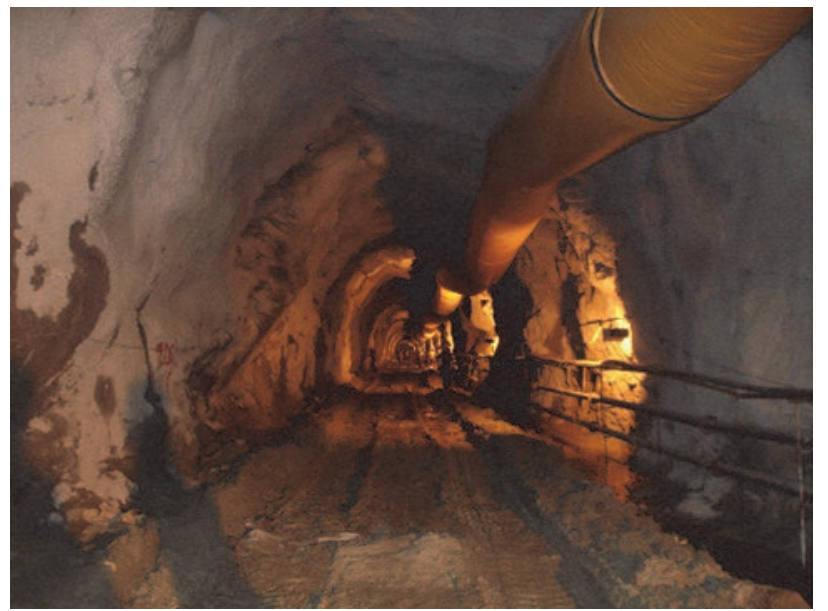

Fig. 2. Photograph showing Head Race Tunnel of SingoliBhatwari Project, Rudraprayag

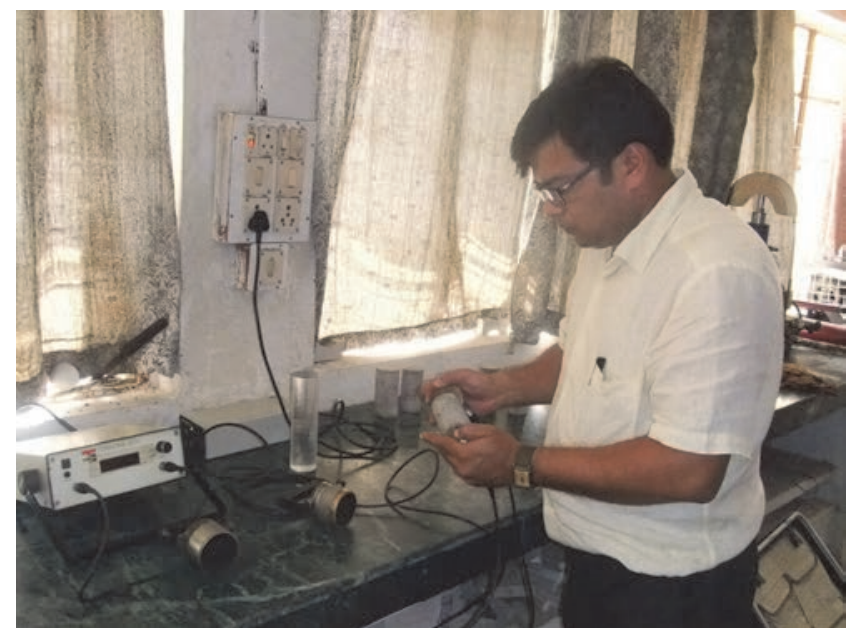

Fig. 3. Laboratory investigation of rock core samples obtained from the experimental sites 
TABLe-1: Geotechnical Properties of Rock IN EXPERIMENTAL TunNeLs [5,6,7,8]

\begin{tabular}{|l|l|l|l|l|l|l|l|}
\hline $\begin{array}{l}\text { SI. } \\
\text { No }\end{array}$ & $\begin{array}{l}\text { Experimental } \\
\text { Tunnel Site }\end{array}$ & Predominant Rock Type & $\begin{array}{l}\boldsymbol{\sigma}_{\mathbf{t}} \\
\mathbf{M P a}\end{array}$ & $\begin{array}{l}\mathbf{V} \mathbf{m} / \mathbf{s} \\
\mathbf{m}\end{array}$ & $\begin{array}{l}\mathbf{E} \\
\mathbf{M P a}\end{array}$ & Data Set & Range of Q \\
\hline 1 & HRT SBHEP & Quartz Biotite Schist & 6.71 & 3267 & 12600 & 27 & $0.8-1.1$ \\
\hline 2 & HRT TVHEP & Augen Gneiss & 8.7 & 5400 & 27900 & 30 & $0.03-1.68$ \\
\hline 3 & BPT TVHEP & Quartzite & 12.4 & 6200 & 55500 & 20 & $2.7-11.1$ \\
\hline 4 & AA7 PSP & $\begin{array}{l}\text { Phyllitic Quartzite Thinly } \\
\text { Bedded (PQT) }\end{array}$ & 4.3 & 5400 & 10500 & 24 & $3.6-4.3$ \\
\hline 5 & AA10R PSP & $\begin{array}{l}\text { Phyllitic Quartzite Massive } \\
\text { (PQM) }\end{array}$ & 7.2 & 6000 & 12700 & 12 & $6.8-17.8$ \\
\hline
\end{tabular}

Notations: $\sigma_{\mathrm{t}}$ : Tensile strength, $\mathrm{V}_{\mathrm{p}}$ : P-wave velocity, E: Young Modulus; $\mathrm{V}_{\mathrm{cr}}$ : Critical peak particle velocity; SBHEP: Singoli-Bhatwari Hydroelectric Project; TVHEP: Tapovan Vishnugaad Hydroelectric Project, Tapovan; PSP: Pump Storage Plant, Tehri

\section{ANALYSIS}

The data were analysed to identify the influence of different parameters in the prediction of overbreak (\%) induced by blasting. The average and maximum overbreak were correlated with the maximum charge per delay, $W$. The variation of overbreak in respect of maximum charge per delay is shown in Fig.4. It is evident from this figure that the maximum overbreak increases with the increase in maximum charge per delay in more than $20 \%$ cases in $25-30 \mathrm{~kg}$ range. Whereas, average overbreak increases approximately 13\% cases beyond $30 \mathrm{~kg}$ of maximum charge per delay. The difference of average and maximum overbreak increases with the increase in maximum charge per delay indicating the predominance of higher maximum charge per in overbreak scenario around underground openings.

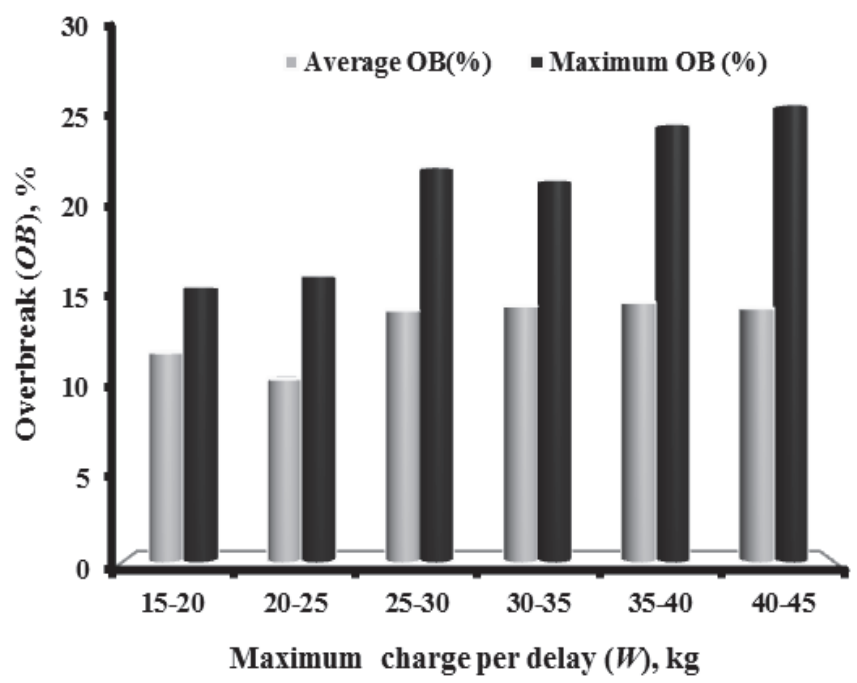

Fig. 4 Variation of observed overbreak with maximum charge per delay

The variations of average overbreak with specific charge, $q$, is shown in Fig. 5. The commonly used specific charge lies in the range of 1.2 to $2.0 \mathrm{~kg} / \mathrm{m}^{3}$ which corresponds overbreak in the order of $10-12 \%$. There is increase in overbreak with the increase in specific charge beyond 2.0 $\mathrm{kg} / \mathrm{m}^{3}$. The specific charge greater than $2.5 \mathrm{~kg} / \mathrm{m}^{3}$ may result in overbreak as high as $20 \%$ and more. Earlier studies showed that a tunnel of cross-sectional area less than $20 \mathrm{~m}^{2}$ requires specific charge greater than $2.0 \mathrm{~kg} / \mathrm{m} 3$ due to higher confinement $[9,10]$. As the size of opening increases, the specific charge reduces. In openings having large crosssectional area, higher specific charge indicates availability of surplus explosive energy. The surplus unutilized explosive energy is converted into blast vibration causing higher overbreak.

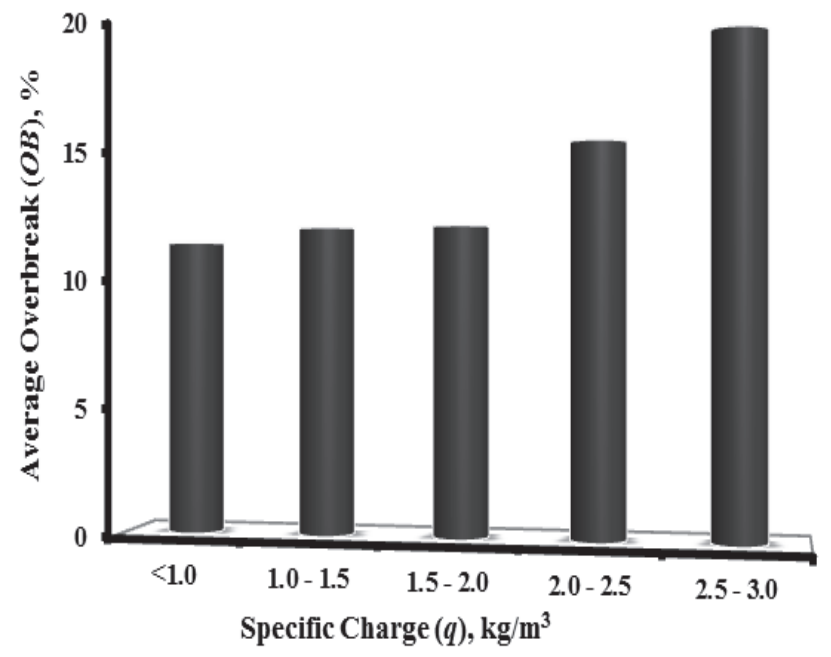

Fig. 5 Variation of average overbreak with specific charge, $q$

Blast induced damage to the surrounding rock mass, either in the form of over-break or damaged zone or both, depends significantly upon the quality of rock mass. figure 6 shows the variation of over-break with the rock mass quality, Q.It may be noted from Fig.6 that the average overbreak is highest for the lower class of rock mass which, then decreases with the increase in rock mass quality. In case of good rock mass, the average overbreak value reduces approximately by $6 \%$.

Figure 7 shows the variation of average overbreak with the ratio of perimeter charge factor and advancement factor $\left(q_{p} / A_{f}\right)$. The term $q_{p} / A_{f}$ measures the optimal utilisation of explosive energy and progressive enlargement of the tunnel. It is established that charging in perimeter holes have 
significant impact on resultant overbreak around an underground opening. It was observed [2] that perimeter powder factor (charge factor) is directly proportional to the over-break and under-break. Analysis of observed data from the experimental blasts shows that the ratio of $q_{p} / A_{f}$ is even better correlated with overbreak in underground construction (Fig.7).

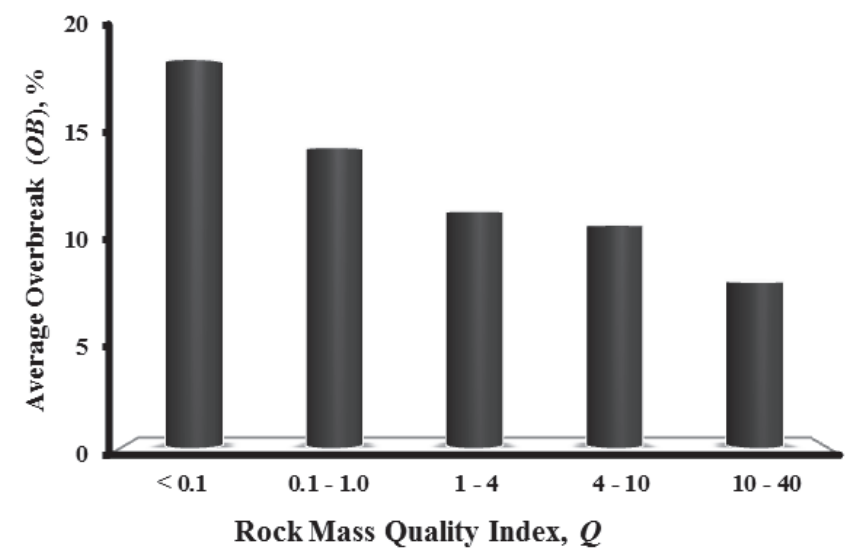

Fig. 6 Variation of average overbreak with rock mass quality index, $Q$

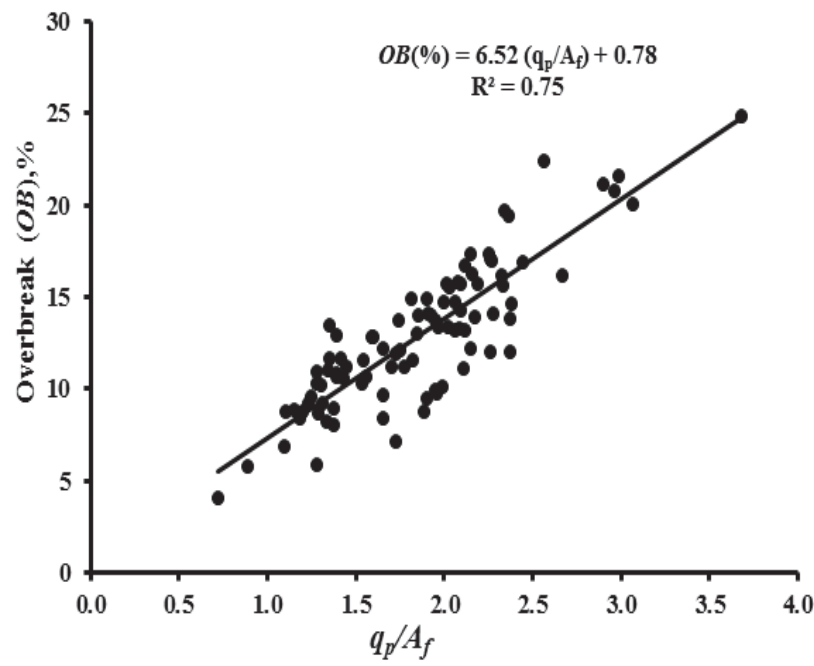

Fig. 7: Plot of observed overbreak (\%) and $q_{p} / A_{f}$

Higher perimeter charge factor $\left(q_{p}\right)$ gives rise to greater overbreak. Overbreak caused by perimeter charge factor can be reduced by optimum advancement in a blasting round. This is due to the availability of better of free face and lesser burden on the contour holes. Greater advancement may reduce negative impacts of perimeter charge factor on overbreak.

Another aspect of blast induced damage as revealed in Fig. 7 is that a better advancement in a blast round will optimally utilise the explosive energy and hence damage to the rock mass will be reduced. Higher advancement enhances the utilization of explosive energy in productive work, i.e. breaking and displacement of rock pieces. The unutilized explosive energy would otherwise be converted into seismic waves and the resultant effect will be higher vibration impacts in the surrounding rock mass. Better advancement also provides free face to contour holes. In tunnel blasting, better advancement ensures sequential initiation of holes and progressive initial cut which ensures less damage to the surrounding rock mass.

The focus was made on ten cases of confinement factor with different cross-sectional area and hole depth. In all the ten cases, confinement factor was normalised with rock mass quality index $Q$. The plot of average overbreak with normalized confinement factor is presented in Fig.8. It is clear that average overbreak increases with increase in confinement factor. Greater depth of hole beyond optimum value will increase overbreak substantially due to increase in confinement factor.

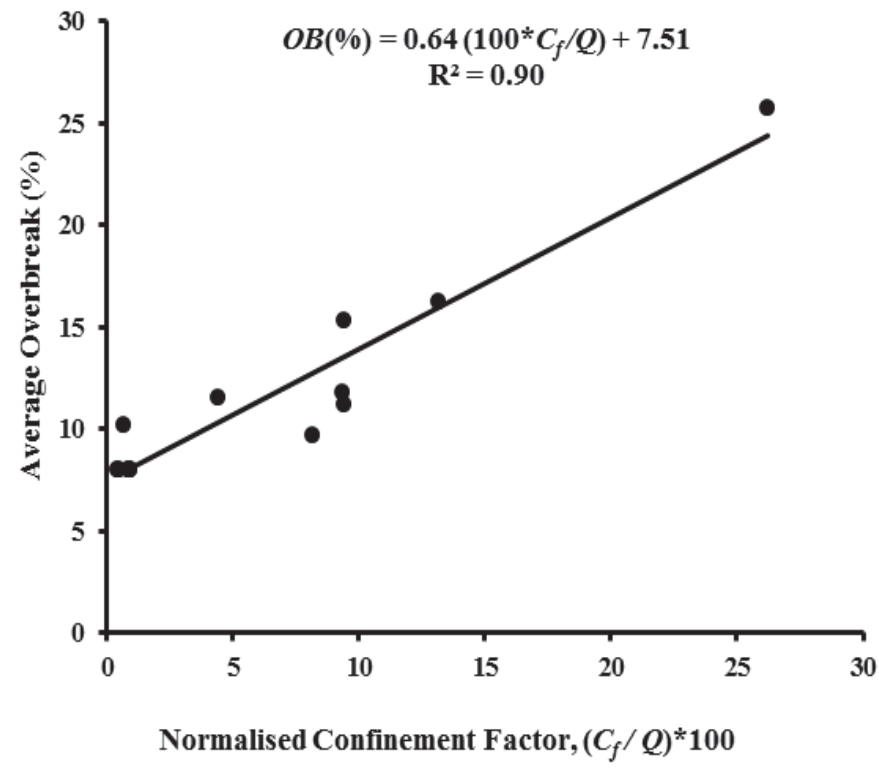

Fig. 8 Plot of average overbreak versus normalised confinement factor $\left(C_{f} / Q\right)$

\section{SCALE EFFECT ANALYSIS}

The overbreak in underground excavation is influenced by the block size of rock mass with respect to size of opening which is also termed as scale effect. An index named 'scale effect' representing the ratio of tunnel cross-sectional area (a) and block size has been formulated and analysed. Block size is a ratio of $R Q D$ and Joint number, $J_{n}$. Higher value of 'scale index' indicates the opening in highly fractured rock mass whereas, lower value indicates the opening in massive rock formation. Overbreak will be higher for higher values of 'scale index' and vice-versa. Figure- 8 shows the effect of 'scale index' on resulting overbreak. It may be observed that as 'scale index' increases, the resulting overbreak increases. 'Scale index' lower than 3 resulted in overbreak less than $10 \%$. The range of overbreak was found to be greater than $25 \%$ for 'scale index' of 4 and above. Whereas, the range of overbreak lies between 4 and 12\% for 'scale index' lower than 4 and it lies between 8 and $25 \%$ for 'scale index' greater than 4 . 
The scale effect analysis may be useful in deciding the allowable limit of overbreak while framing the contract guidelines. In many countries, special standards to regulate the overbreak and deviation from the designed profile are recommended. The Swiss Society of Engineer and Architects recommend overbreak profile to be lower than $0.07 \sqrt{ } \mathrm{a}$ with maximum limit of $0.4 \mathrm{~m}$ [1]. The Construction Manual guidelines recommend 150 - $200 \mathrm{~mm}$ of overbreak in crown area and $100-150 \mathrm{~mm}$ in side-walls $[11,12,13]$. Using this 'scale index' for a given rock mass, range of allowable overbreak can be suggested.

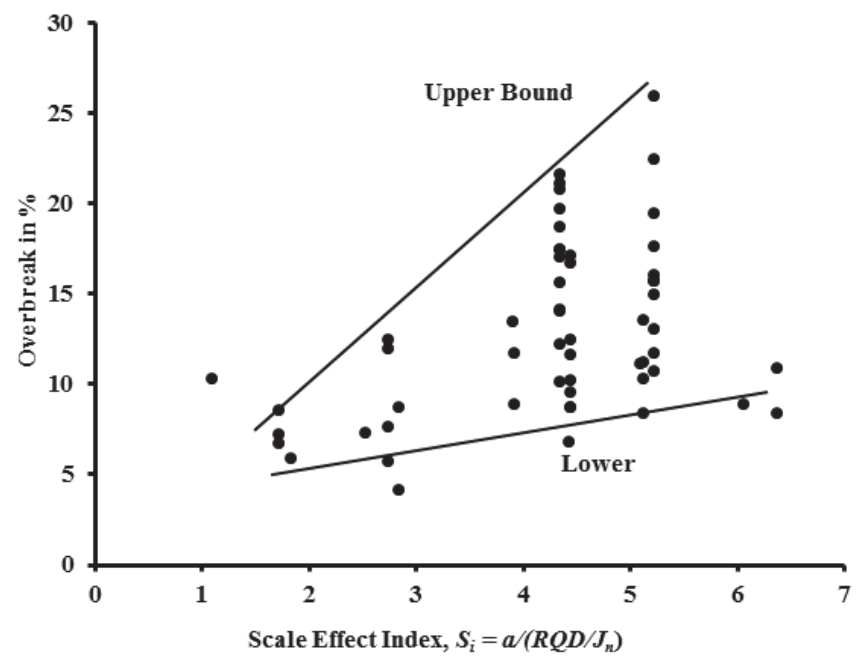

Fig. 9 Plot of 'scale effect index' versus overbreak (\%)

\section{EMPIRICAL DETERMINATION OF OVERBREAK}

It is evident from the above discussions that overbreak is directly proportional to specific charge $(q)$, maximum charge per delay $(W)$, perimeter charge factor (qp)and confinement factor whereas it is inversely proportional to rock mass quality index $(Q)$ and advancement factor $\left(A_{f}\right)$. The data monitored during field study were grouped together to obtain regression analysis and in Fig.9. The predictor equation of overbreak (in \%) based on the observations of 113 experimental blast is given in equation1. It encompasses various influencing parameters of underground construction works. As peak particle velocity $(P P V)$ of vibration is dependent significantly on maximum charge per delay rather than total charge used in the blasting round, the parameter ' $W$ ' becomes an appropriate for explosive energy.

$$
O B(\%)=0.854 * \frac{q}{Q^{0.15}}\left(\frac{W * d}{a}+\frac{3.89 q_{p}}{A_{f}}\right)+0.69
$$

Where,

$D_{d}=$ damage distance, $\mathrm{m}$,

$q_{p}=$ perimeter charge factor, $\mathrm{kg} / \mathrm{m}^{3}$,

$W=$ maximum charge per delay, $\mathrm{kg}$,

$q=$ specific charge, $\mathrm{kg} / \mathrm{m}^{3}$,

$Q=$ rock mass quality index (Barton' $Q$-system)
Perimeter charge factor $\left(q_{p}\right)$ represents energy concentration in contour holes irrespective of the outcome of blast design. Its effect can be minimised by better advancement rate.

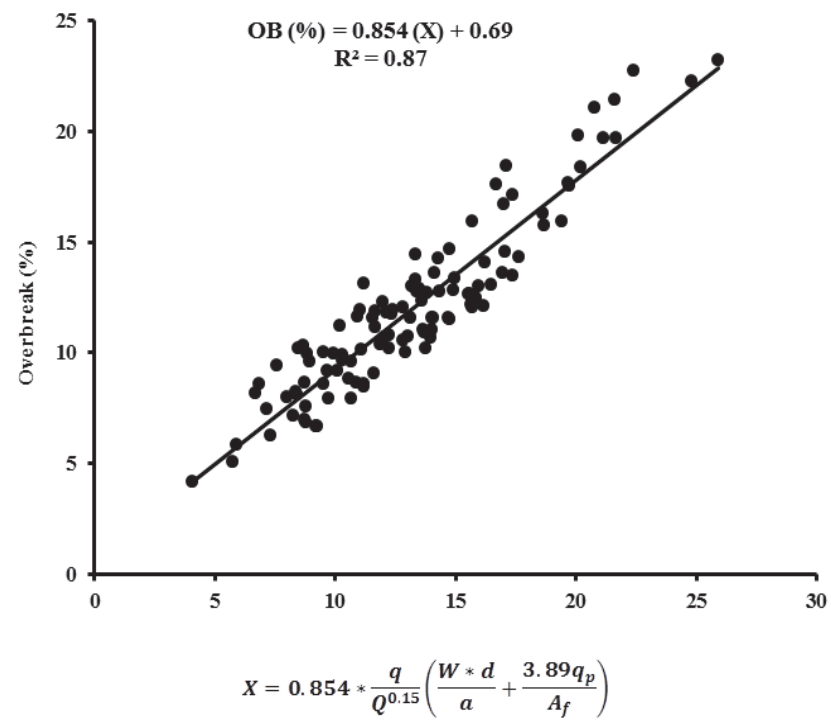

Fig. 10 Plot of factor X versus observed overbreak (\%)

$$
\begin{aligned}
& d=\text { hole depth, } \mathrm{m}, \\
& l=\text { pull, } \mathrm{m}, \text { and } \\
& a=\text { tunnel cross-sectional area, } \mathrm{m}^{2} .
\end{aligned}
$$

Effect of tunnel cross-sectional area is considered in the form of confinement factor. Larger cross-sectional area provides lesser confinement. For a given tunnel size, depth of hole can play a crucial role in defining overbreak zone. Effect of hole depth in respect of damage in the form of overbreak will be less in large size tunnel and more in smaller tunnel size. A poor blast design will result in more overbreak. In the proposed correlation, advancement factor has been considered to be a representative parameter for performance of the blast design. Greater advancement rate utilizes explosive energy in productive manner and therefore, the overbreak caused by the blast induced vibration is reduced.

Rock mass quality index, $Q$ [14] is used for rock mass characterisation. $Q$ is used in denominator of the proposed predictive model to indicate that a better rock mass quality would sustain higher level of blast vibration and therefore the overbreak induced by blasting will be lower. The proposed correlation is developed from a wide range of $\mathrm{Q}$ value which includes extremely poor rock mass to good rock mass condition and therefore equation-1 can be used for prediction of overbreak for these classes of rock mass. Smooth wall blasting is mostly used in underground for controlling of overbreak. In smooth wall blasting, closelyspaced holes are used. These holes are charged with lower charge factor. In smooth wall blasting, values of perimeter charge factor will be very less and hence the predicted overbreak will be reduced. Proposed predictive model can discriminate between conventional and smooth wall blasting techniques. 


\section{CONCLUSIONS}

A comprehensive field investigation have been carried out at five tunnel construction sites to evolve empirical equations for estimation of over-break (\%) using readily available site parameters. Data of 113 blasting experiments in different rock mass from extremely poor to good have been taken into account.

Analysis of field data reveals that the over-break in underground blasting operations is significantly influenced by the perimeter charge factor and maximum charge per delay. They are found to be significant in poor quality rock mass. Parametric analysis reveals that the deteriorating effects of blast design parameters are enhanced in poor quality of rock mass. 'Scale effect' analysis has been carried out by formulating an index which is the ratio of tunnel cross-sectional area and block size of rock mass. The analysis reveals that the range of overbreak (\%) lies between 8 and $25 \%$ for openings in rock mass having Si greater than 4.

It has been observed that the over-break (\%)can be expressed in terms of rock mass quality index $(Q)$, perimeter charge factor $\left(q_{p}\right)$, specific charge $(q)$, maximum charge per delay $(W)$, advancement $\left(A_{f}\right)$ and confinement factors $\left(C_{f}\right)$. As the proposed model is based on readily available site parameters, it may be useful to the practicing engineers and geologists while optimising the support design.

Achieving advancement through optimized blast pattern is advantageous in reducing blast induced damage to the surrounding rock mass. Over-break is found to be the result of complex interactions of improper sequences of excavation, unscientific blasting practices and inadequate primary support. Presence of unfavourable joints, their directions, non-cohesive filling materials and adverse ground water conditions aggravate occurrence of immediate overbreak.

\section{ACKNOWLEDGMENT}

The Authors express their gratitude to the Managements of National Thermal Power Corporation Ltd., New Delhi, THDC India Ltd., Rishikesh, M/s Larsen \& Toubro (L\&T), Tapovan-Vishnugaad Hydropower Project for their cooperation and help. Thanks are also due to the engineers and geologists of L\&T Singoli-Bhatwari Hydropower Project for providing great help during field investigations.

\section{REFERENCES}

[1] Innaurato, N., Mancini, R., and Cardu, M., 1998. On the influence of rock mass quality on the quality of blasting work in tunnel driving, Tunnelling and Underground Space Technology Vol. 13, No. 1 pp. 81 -89 .

[2] Ibarra J. A., Maerz N. H. and Franklin .J. A. 1996. Overbreak and underbreak in underground openings Part 2: causes and implications, Geotechnical and Geological Engineering, Vol. 14, No.3, pp. 325 340

[3] MacKown, A.F., 1984. Perimeter controlled blasting for underground excavations in fractured and weathered rocks. Bull. Assoc. Engg. Geol. Vol. 23, No. 4, pp. 461-478.
[4] IS: 9401-Part 16, 1999. Code for Method of measurement of works in river valley projects (dams and appurtenant structures) Bureau of Indian Standards, New Delhi.

[5] NTPC, 2006. Detailed Project Report, Tapovan Vishnugaad Hydroelectric Project Vol. 4, Part-II, NTPC, New Delhi, India, 262 p.

[6] NTPC, 2010. Detailed Project Report (By-pass Tunnel), Tapovan Vishnugaad Hydroelectric power project NTPC, New Delhi, India, $132 \mathrm{p}$.

[7] PSP, 2007. Detailed project report of Pump Storage Plant project, Tehri Development Corporation India Ltd., Rishikesh, Vol. 2, 432 p.

[8] L\&T- SBHEP, 2007. Singoli-Bhatwari Hydroelectric Power Project, Detailed Project Report, L\&T-Uttaranchal Hydropower Limited, Vol. 4, $306 \mathrm{p}$.

[9] Olofsson, S.O., 1990. Applied Explosives Technology for Construction and Mining, Applex, Arla, Sweden, 303 p.

[10] Chakraborty, A.K., Murthy, V.M.S.R. \& Jethwa, J. L., 1998. Blasting problems in underground constructions through Deccan Trap Formation: some experiences at Koyna Hydro-electric project, stageIV, Tunnelling and Underground Space Tech. Vol. 11 No. 3, pp. 311-324.

[11] Cunnigham, V.B. and Geotzsche A. F., 1990. The specification of blast damage limitations in tunnelling contracts, Tunnelling and Underground Space Technology, Vol. 5, No.3, pp. 193-198.

[12] Korea Highway Corporation, 2000. Design guide of the optimum blasting patterns for minimizing overbreak.

[13] Mandal, S.K., Singh, M.M., Bhagat, N.K., Dasgupta, S., 2005. Causes of overbreak and influence of blast parameters for smooth undamaged wall, Proc. Intl. Sym. on Advances in Mining Technology and Management, November 30-December, 2, IIT, Kharagpur, pp. 49-58.

[14] Barton, N., Lien, R. \& Lund, J., 1974. Engineering classifications of rock masses for the design of tunnel support, Rock Mech., Vol. 6, pp.189-236. 